\title{
Collapse loads of steel frameworks allowing for the effect of strain-hardening
}

\author{
by \\ M. R. Horne, M.A., Sc.D., M.I.C.E., A.M.I.Struct.E. \\ and \\ I. C. Medland, B.Sc. (N.Z.), M.E. (N.Z.), Ph.D. $\dagger$
}

Mr M. W. Chin (Research Student, University of Manchester) wrote that he welcomed the publication of the Paper because he was engaged in work closely connected with the subject matter dealt with by the Authors. He was concerned with an investigation into the behaviour of structures composed of the new high yield-stress steel to B.S. 968 and the applicability of the plastic theory to the design of such structures.

37. As part of this investigation, he had conducted a number of bending tests on simply supported beams of more realistic I-sections in the new steel to check the applicability of the Authors' theories to the estimation of the strain-hardening characteristic of such beams. He had found that the rigid-plastic-strain-hardening (r.p.s.h.) and rigid-plastic-rigid (r.p.r.) theories both gave good estimates of the strain-hardening characteristic of high tensile steel beams and that the basic r.p.r. theory could be used as a suitable basis for a design method.

38. He had also investigated the Authors' proposals for preparing design charts which would give the failure load of a frame in terms of its simple plastic collapse load. As a result of this investigation, he had produced a complete set of charts for varying pitches which would facilitate the design of pitched roof portal frames. Examples of such charts were presented in Figs 20 and 21 which gave the failure loads of pinned-and fixed-base pitched roof portal frames respectively for an angle of pitch of $22 \frac{1}{2}^{\circ}$ in terms of their simple plastic-collapse loads. The horizontal scale was in terms of the ratio of span $L$ to height to eaves $h_{1}$ while the vertical scale was in terms of an effective slenderness ratio denoted by $\left(k \nu \sigma_{y} / E\right)(L / d)$ where $k$ was termed the strainhardening factor, $\nu$ was the shape factor, $d=$ depth of section, $\sigma_{y}=$ yield stress and $E=$ the modulus of elasticity.

39. The theoretical basis of these charts was similar to that which had been given by the Authors except that instead of using the r.p.s.h. theory to calculate the failure loads of a wide range of frames, complete elastic-plastic analyses had been carried out with the aid of two computer methods of structural analysis developed at Manchester University and which made allowances for both the effects of instability and strain-hardening. Details of these computer programs could be found elsewhere. ${ }^{15}$

40. It was of interest in this case to apply these charts to the prediction of the failure loads of the frames tested by Professor Medland, and to compare them with the reductions in carrying capacity below the plastic-collapse load that would be required according to recent recommendations. ${ }^{16}$ Using the values of the various

* Proc. Instn civ. Engrs, 1966, 33 (Mar.) 381-402.

$\uparrow$ Since the publication of the Paper, Dr Medland has been appointed to the Chair of Civil Engineering, University of Toronto, Canada. ${ }_{15}$ The references appear on p. 687. 


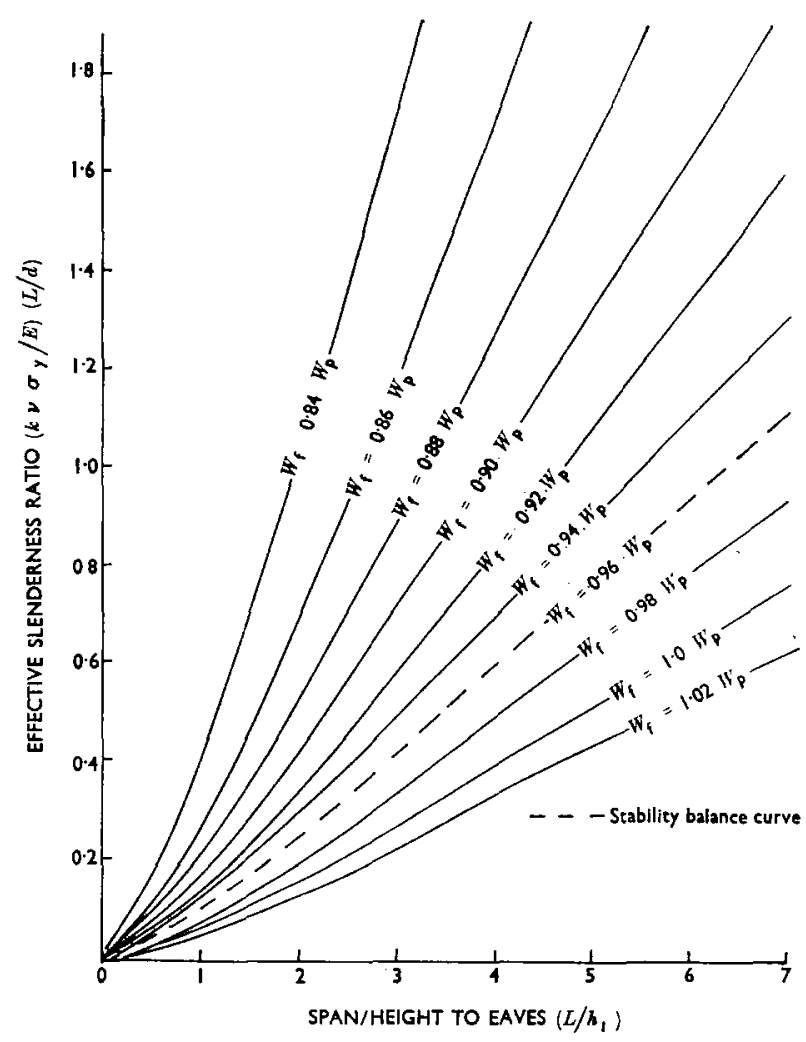

FIG. 20: DESIGN CHART FOR PINNED-BASE FRAMES, $\phi=22 \frac{1}{2}^{\circ}$

factors given in the Paper, viz. $k=7 \cdot 0, v=1 \cdot 26, \sigma_{y}=16 \cdot 0$ tons/sq. in., $E=13400$ tons/ sq. in., $d=1 \frac{1}{4}$ in. and $L=87$ in. together with the appropriate span to height to eaves ratios, the failure loads of the frames tested had been obtained from Figs 20 and 21 . These were given in Table 2 which compared the actual test results with those given by the Authors' r.p.s.h. theory, the charts presented by Baker in B.C.S.A. No. 21 and the Writer's charts. It could be seen that the Writer's charts gave estimates of the failure loads which were generally in close agreement with the experimental results and also the Authors' predictions, whilst the use of the charts presented in B.C.S.A. No. 21 led to conservative estimates for the frames on account of the neglect of strain-hardening.

41. Full-scale tests on several pitched roof frames in steel to B.S. 968 had been carried out by $\mathrm{Mr}$ Chin and the results of these tests provided further experimental evidence on which to recommend the use of the charts presented in Figs 20 and 21. It should be mentioned that in using these charts the designer should check for column stability and this could be done by reference to the design charts presented in B.C.S.A. Publication No. 23. ${ }^{3}$

42. It was anticipated that a complete set of charts similar to those of Figs 20 and 21 would be available in published form in the not too distant future. 


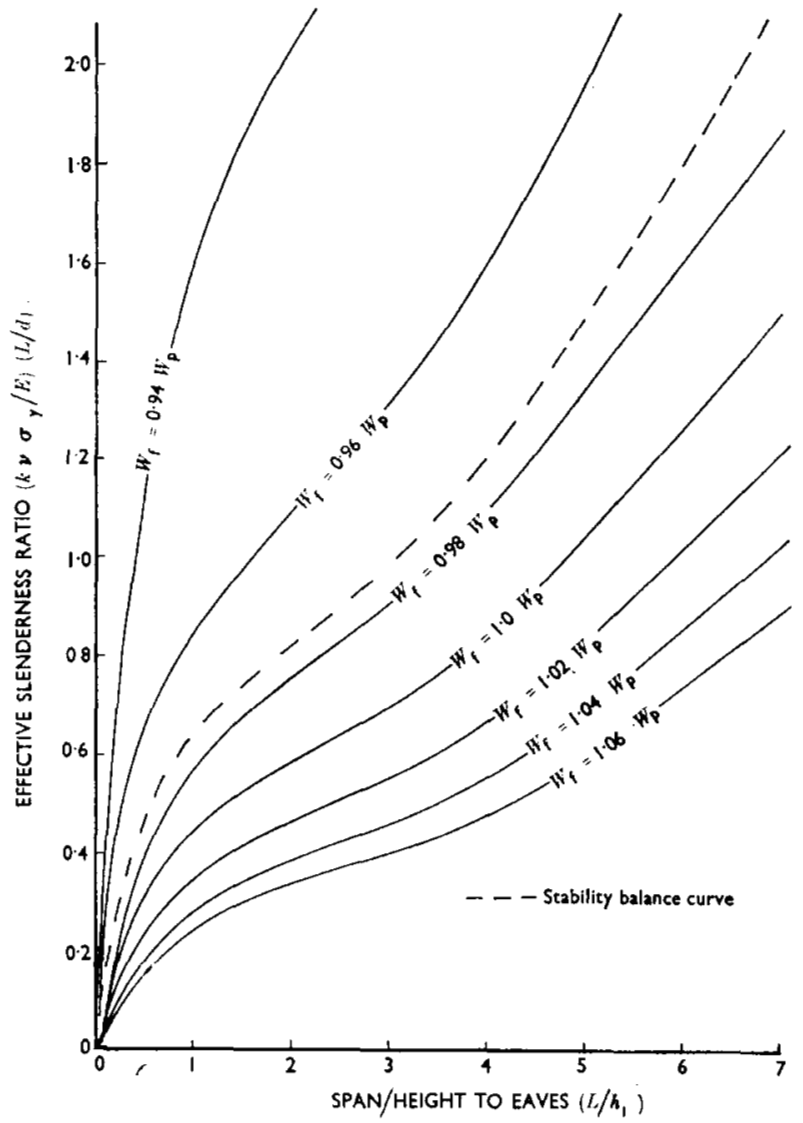

Fig. 21: Design Chart for FIXed-base frames, $\phi=22 \frac{1}{2}^{\circ}$

TABLE 2

\begin{tabular}{|c|c|c|c|c|c|c|}
\hline \multirow{2}{*}{$\begin{array}{c}\text { Test } \\
\text { frame } \\
\text { no. }\end{array}$} & \multirow[t]{2}{*}{$L / h_{1}$} & \multirow{2}{*}{$\begin{array}{l}\text { Simple } \\
\text { plastic } \\
\underset{l b}{\text { load } W_{\mathrm{p}}}\end{array}$} & \multirow{2}{*}{$\begin{array}{l}\text { Actual } \\
\text { failure } \\
\text { load } \\
\% W_{\mathrm{p}}\end{array}$} & \multicolumn{3}{|c|}{ Theoretical failure load } \\
\hline & & & & $\begin{array}{l}\text { Authors' } \\
\text { r.p.s.h. } \\
\% W_{\mathrm{p}}\end{array}$ & $\begin{array}{c}\text { Baker's } \\
\text { charts } \\
\% W_{\mathbf{p}}\end{array}$ & $\begin{array}{c}\text { Writer's } \\
\text { charts } \\
\% W_{\mathrm{p}}\end{array}$ \\
\hline $\begin{array}{l}\text { P.P.1 : } \\
\text { P.P.2 : } \\
\text { P.P.3 : } \\
\text { P.P.4 : } \\
\text { F.P.1 : } \\
\text { F.P.2 : }\end{array}$ & $\begin{array}{l}4 \cdot 35 \\
5 \cdot 8 \\
3 \cdot 48 \\
5 \cdot 8 \\
2 \cdot 42 \\
3 \cdot 62\end{array}$ & $\begin{array}{r}956 \\
\\
909 \\
1075 \\
985 \\
1089\end{array}$ & $\begin{array}{c}96 \cdot 2 \\
\text { TEST } \\
92 \cdot 9 \\
97 \cdot 5 \\
100 \cdot 5 \\
104 \cdot 0\end{array}$ & $\begin{array}{c}94 \cdot 1 \\
\text { UNSUCCF } \\
91 \cdot 5 \\
97 \cdot 1 \\
97.5 \\
101.5\end{array}$ & $\begin{array}{c}91 \cdot 35 \\
\text { SFUL } \\
92 \cdot 75 \\
88 \cdot 4 \\
92 \cdot 35 \\
89 \cdot 8\end{array}$ & $\begin{array}{r}95 \cdot 0 \\
\\
92 \cdot 4 \\
98 \cdot 9 \\
99 \cdot 2 \\
102 \cdot 0\end{array}$ \\
\hline
\end{tabular}


Dr J. M. Davies (Engineer, Ove Arup and Partners, Edinburgh) wrote that he had been concerned with extending the Authors' work and had a number of comments to make.

\section{THE FACTOR $k$}

44. The Authors described the results of a series of tests that had been carried out in order to examine the strain-hardening properties of plastic hinges in mild steel members. The material used was a miniature I-section of dimensions 1 in. $\times 1 \frac{1}{4}$ in.

45. The Writer had completed a similar series of tests using commercially available rolled sections, namely 3 in. $\times 2$ in. $\times 4 \frac{1}{2}$ lb R.S.J., and had obtained results that could be compared with those described in the Paper. As with the earlier tests, no correlation had been obtained between the strain-hardening factors determined from bending and tensile tests and so the results would be described solely in terms of the bending properties of the sections.

46. Two tests had been carried out by subjecting simply supported beams of $4 \mathrm{ft} 0$ in. span to two equal point loads symmetrically placed at $1 \mathrm{ft} 0 \mathrm{in}$. centres. For these tests, each beam had been made up of two lengths of R.S.J. tack-welded together side-by-side in order to produce a section twice as strong as the original section for bending about the strong axis and several times as strong for bending about the weak axis. This arrangement had proved to be successful in eliminating the tendency for the beams to buckle laterally when a region of plasticity extended over the length between the loads. From these tests, $k_{\mathrm{m}}=\rho_{\mathrm{s}} / \rho_{\mathrm{y}}$ was found to have values of 8.5 and 9.9 and the corresponding values of $K$ were 76.4 and 90.0 .

47. A number of tests had also been made by loading simply supported beams of various spans with a centrally placed point load. These beams had been adequately braced against out-of-plane buckling and loaded in increments until the full plastic moment at the section beneath the load had been exceeded by approximately $10 \%$ for longer spans increasing to about $14 \%$ for shorter spans. For this load range, the moment-rotation relationship exhibited by a plastic hinge had been found to be approximately linear, and a value of $k_{\mathrm{u}}$ had been found for each test from the best fitting straight line.

48. The results obtained were summarized in Fig. 22, which should be compared with Fig. 9. It could be seen that the coefficient $k_{\mathrm{u}}$ was again not constant, but increased for shorter spans (corresponding to less strain hardening). The reason for this variation in the value of $k_{\mathrm{u}}$ probably lay in the fact that the situation was complicated by the contact stresses that arose beneath point loads. It was known ${ }^{1}$ that these stresses had the effect of raising the apparent value of the full plastic moment and this effect became more important as the cantilever distance $h$ decreased. It therefore seemed likely that the increase in the moment of resistance due to contact stresses, decreasing in its effect as the plastic zone spread outwards, was the main reason why there was an apparent reduction in the strain-hardening effect for shorter spans. If this was in fact the explanation, the adoption of material properties based on tests using simply supported beams subjected to two-point loading would be conservative at low hinge rotations, becoming more exact as the hinge rotation increased. It should be emphasized, however, that any material benefit taken of the effect of strain-hardening was dependent on the provision of adequate lateral restraint to prevent local out-of-plane buckling in the vicinity of plastic hinges, otherwise its effect could be largely lost.

49. Comparing Fig. 9 with Fig. 22, it could be seen that whereas the Writer had obtained values of $k_{\mathrm{u}} / k_{\mathrm{m}}$ that tended, as would be expected, to approach unity for long spans, the Authors had obtained values that tended to approximately $1 \cdot 3$. This discrepancy arose because of an error of fact in the original Paper. The Authors stated that the value of 5.3 quoted for $k_{\mathrm{m}}$ had been obtained from the ratio of the curvature at the onset of strain-hardening to the curvature at yield during a test 


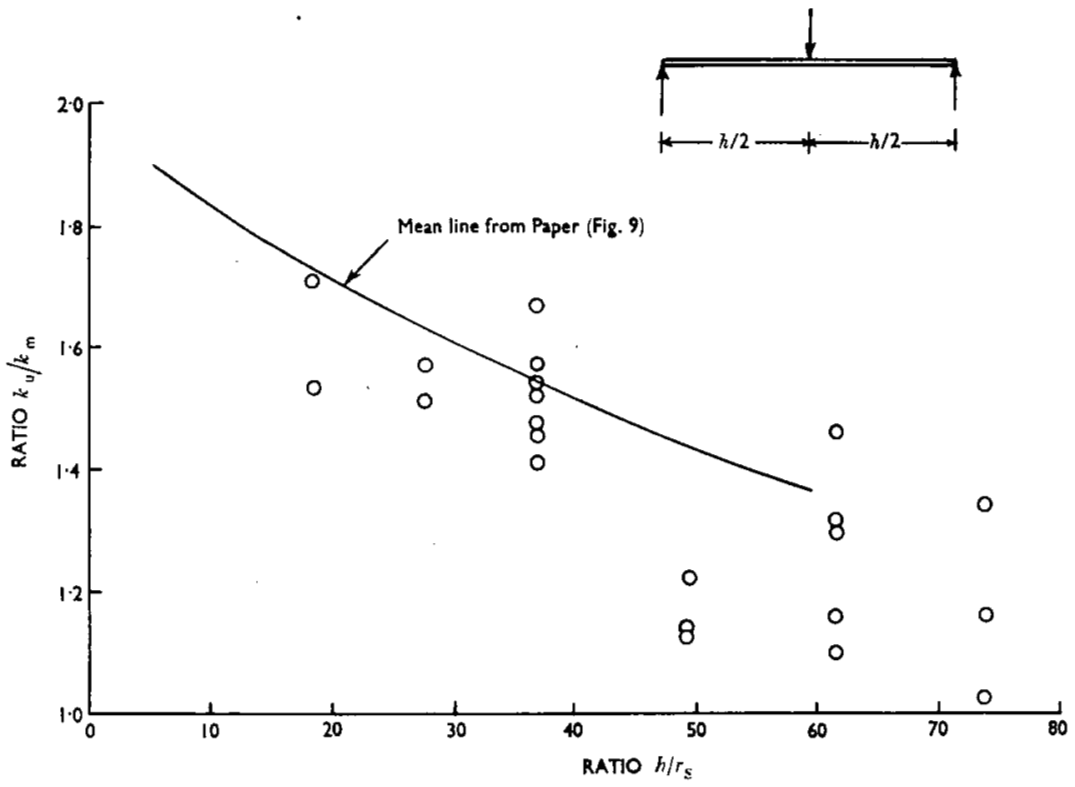

Fig. 22: Strain-HaRdening Behaviour of 3 IN. $\times 2$ IN. $\times 4 \frac{1}{2}$ LB R.S.J.

on a simply supported beam subjected to symmetrical two-point loading. In contrast, Professor Medland stated in ref. 12 that $k_{\mathrm{m}}$ had been obtained as the ratio of the corresponding central deflexions obtained from such a test. Subsequent correspondence with Professor Medland had confirmed that the statement in ref. 12 was the correct one, though he agreed that the curvature ratio was the correct definition of $k_{\mathrm{m}}$ since the deflexion ratio depended on the relationship between the span and the distance apart of the loads.

\section{THE FAILURE LOADS OF FRAMES ALLOWING FOR STRAIN-HARDENING}

50. The Writer had, in the course of his research, ${ }^{15.18}$ written a general computer program that could carry out 'exact' unit shape factor analyses of plane frameworks incorporating the effects of frame instability and strain-hardening. The effect of strain-hardening was included on the basis of the equation

$$
m=\frac{E I}{k_{\mathrm{u}} h} \quad \cdot \quad \cdot \quad \cdot \quad \cdot \quad \cdot \quad \cdot \quad \cdot
$$

which could be derived from equation (3) of the Paper.

51. This program had been used to analyse the frames tested by the Authors and provided a theoretical check on the somewhat empirical method of estimating collapse loads advocated in the Paper. Table 3 summarized the results obtained using this computer program and included, for the purposes of comparison, some of the results given in Table 1 of the Paper. For the two results indicated by '+', the computer had indicated that the frames would be able to carry loads in addition to those shown, which corresponded to the formation of a complete collapse mechanism. In all other cases, the loads shown were those at which an unstable collapse condition had been achieved in the analysis. 
TABle 3: Collapse loads (lB) of Pitched roof PORTal fRames

\begin{tabular}{l|c|r|r|r|r|r|r}
\hline Frame & $k_{\mathrm{u}}$ & $\begin{array}{c}\text { Simple } \\
\text { plastic- } \\
\text { collapse } \\
\text { load }\end{array}$ & $\begin{array}{c}\text { Experi- } \\
\text { mental } \\
\text { collapse } \\
\text { load }\end{array}$ & $\begin{array}{c}\text { Rankine } \\
\text { load }\end{array}$ & $\begin{array}{c}\text { R.p.s.h. } \\
\text { theory } \\
\text { (Authors') }\end{array}$ & $\begin{array}{c}\text { Computer- } \\
\text { no strain- } \\
\text { hardening }\end{array}$ & $\begin{array}{c}\text { Computer-- } \\
\text { with strain- } \\
\text { hardening }\end{array}$ \\
\hline P.P.1 . & 7.0 & 956 & 920 & 828 & 900 & 775 & 908 \\
P.P.3 & 6.5 & 909 & 844 & 766 & 832 & 741 & 841 \\
P.P.4 & 6.5 & 1075 & 1048 & 950 & 1044 & 860 & 1106 \\
F.P.1. & 6.7 & 985 & 990 & 937 & 960 & 912 & $972+$ \\
F.P.2. & 7.2 & 1089 & 1130 & 1051 & 1105 & 985 & $1108+$ \\
\hline
\end{tabular}

52. It could be seen that the results given by the r.p.s.h. theory were consistently slightly conservative when compared with the more exact analysis using a computer. Agreement with the experimental results was good with the possible exception of frame P.P.4 which had failed before the predicted collapse load had been attained. It would appear ${ }^{12}$ that this frame had suffered a premature failure due to local buckling of the rafters.

53. The theoretical results presented above would appear to add weight to the suggestion that the design charts prepared by the Authors were sufficiently accurate to be used in the design of pitched roof frames. It should, however, be mentioned that the amount of strain-hardening exhibited by the 1 in. $\times 1 \frac{1}{4}$ in. I-sections, the properties of which had been used in the preparation of these charts, was rather higher than that obtained from subsequent experiments on more realistic structural sections. For this reason it was desirable that further charts should be produced based on a more conservative estimate of the strain-hardening properties of structural steel sections.

54. Perhaps it should also be mentioned that the 'exact' failure loads neglecting strain-hardening all fell significantly below the Rankine load (equation (1)) and that for these frames the Rankine load was invalid as a measure of the ultimate load unless the beneficial effect of strain-hardening was taken into account.

\section{STRAIN-HARDENING AND GÉNERAL STRUCTURES}

55. The Authors suggested that the stability of the rigid-plastic collapse mechanism could be used in general as a measure of whether or not a premature failure might occur due to frame instability. The experience of the Writer would indicate that the theory given in the Paper was not of general application in this way, owing to changes in the modes of collapse of more complex structures that were brought about by frame instability. The general tendency was for 'combined' modes to be replaced by 'sway' modes which were much less influenced by strain-hardening. Examples had been given ${ }^{15,18}$ in which the rigid-plastic collapse mechanism was stable when an allowance for strain-hardening was made, but exact analysis had shown the frame to suffer unstable collapse in a quite different mode and with a minimal increase in the failure load due to strain-hardening.

56. This state of affairs would seem to suggest that the theory given by the Authors was only applicable to simple structures that had a small number of alternative collapse modes. Since pitched roof portal frames fell into this category, the particular analyses and design curves which had been given remained valid and provided useful information regarding the behaviour of these frames in the elastic-plastic range.

The Authors, in reply, thanked Mr Chin for his comments, which showed how the work described in the Paper had now been carried further, resulting in the production 
of design charts for portal frames in steel to B.S. 968 . When the work had been started, it had been hoped that some universally applicable simple procedure might be found for calculating failure loads in rigid plane frames allowing both for change of geometry and strain-hardening, but this had proved impossible, and the production of design charts was a natural alternative outcome of the work.

58. Dr J. M. Davies had presented various points of interest. Now that computer programs for elastic-plastic failure loads (allowing for strain-hardening) were available, there was likely to be less application for the Authors' r.p.s.h. theory, although the latter possessed the advantage that hand calculations could be tackled for simple frames. The agreement between r.p.s.h. theory and the computer solutions with strain-hardening produced by Dr Davies appeared to be sufficiently good for results from r.p.s.h. theory to be accepted as accurate for practical purposes.

59. The comments made by Dr Davies on the indifferent correlation between the Rankine-Merchant load and 'exact' failure loads neglecting strain-hardening were noted. Wide experience had shown that the value of the Rankine-Merchant load lay in it being virtually always a lower bound on practical collapse loads. This still appeared to be the case, and was perhaps as much as could be expected from such a simple formula.

60. Dr Davies had commented that the strain-hardening stability of the rigidplastic collapse mechanism was not always a reliable guide to the possible incidence of significant reductions in carrying capacity due to frame instability because of the intrusion of other failure modes. It was too much to ask that any one simplified theory should give the answer for all types of frame, but one might try several simplified theories and adopt the most pessimistic. Thus, where a 'sway' mode took over from a 'combined' mode, the resulting decrease in failure load might not be indicated by considering the strain-hardening stability of the rigid-plastic mechanism, but would certainly be revealed in the Rankine-Merchant load. There might here be scope for deriving a more successful formula based on the rigid-plastic failure load, the elastic critical load and the strain-hardening stability condition. One might always generate failure loads either by a computer solution or by adopting design charts for particular structures, but there remained the possibility of deriving some general but simple hand calculation procedure. Concepts such as the RankineMerchant load and rigid-plastic-rigid stability balance were to be regarded as steps in this direction. Rigid-plastic-rigid theory appeared to give useful results for simple structures with a small number of alternative collapse modes, and it was for this type of frame that the method was recommended.

\section{REFERENCES}

15. Davies J. M. The stability of plane frameworks under static and repeated loading. Ph.D. thesis, University of Manchester, 1965.

16. BaKer J. F. Plastic design in steel to B.S.968. Publ. No. 21, British Constructional Steelwork Association, London, 1963.

17. Horne M. R. Plastic design of columns. Publ. No. 23, British Constructional Steelwork Association, London, 1964.

18. Davies J. M. Frame instability and strain hardening in plastic theory. Proc. Am. Soc. civ. Engrs, Struct. Div. 1966 (Jun.). 